\title{
Evaluation of Glycated Albumin to Glycated Hemoglobin Ratio as a Predictor for Esophageal varices and its Risk of Bleeding
}

\author{
Ahmed Mohammed Osama, EL-Sayd Mohammed Mohie EL-Dien, \\ Mohammed Abd El-Hamid Bsyoni, Mostafa Shehata EL-said
}

\author{
Department of Tropical Medicine, Faculty of Medicine, Al-Azhar University, Cairo, Egypt
}

Corresponding author: Mostafa Shehata EL-said, E-mail: mosgit86@gmail.com

\begin{abstract}
:
Background: Variceal hemorrhaging due to portal hypertension is a severe complication of liver cirrhosis. Although several biomarkers have been reported as predictors of the presence of varices, it is still difficult to assess the risk of variceal bleeding without esophagogastroduodenoscopy (EGD). The ratio of glycated albumin (GA) to glycated hemoglobin (HbA1c) was reported to increase with the progression of liver fibrosis. The aim of the study was to investigate whether the GA/HbA1c ratio is related to the severity and bleeding risk of the varices. Aim of the work: goal of our study was to assess the value of Glycated albumin to Glycated hemoglobin ratio in the prediction of esophageal varices and assessing its risk of bleeding. Methods: We measured the GA/HbAlc ratio of HCV-related cirrhotic patients and analyzed its relationship with the presence and bleeding risk of varices. Results: The $\mathrm{GA} / \mathrm{HbA} 1 \mathrm{c}$ ratio was higher in the patients who had the varices with a high risk of hemorrhage than in the patients with a low risk of bleeding. In addition, the GA/HbA1c ratio was higher in patients with varices than that in patients without varices. Furthermore, the GA/HbA1c ratio was the most significantly different parameter of all the factors examined, including the platelet count, prothrombin activity and albumin level. Conclusion: The GA/HbA1c ratio is increased in patients with varices and with the bleeding risk of the varices.
\end{abstract}

Keywords: Liver cirrhosis; Portal hypertension; Esophageal varices; Glycated albumin; Glycated hemoglobin.

\section{INTRODUCTION}

Portal hypertension is a major complication of liver cirrhosis and can be a direct cause of variceal hemorrhage and of bleeding-related death.

Therefore, esophagogastroduodenoscopy (EGD) is considered to be necessary for all cirrhotic patients to evaluate the risk of variceal bleeding ${ }^{(1,3)}$.Three factors identify patients at a high risk of bleeding from varices: a large variceal size, red signs on the varices and advanced liver disease (Child-Pugh class B or C) ${ }^{(4)}$. Several biochemical parameters have been reported as predictors of the presence of varices, such as a low platelet count, an advanced Child-Pugh class, hypoalbuminemia and low prothrombin activity ${ }^{(5,8)}$. However, it is still difficult to predict the presence of varices without EGD. In addition, with regard to compensated cirrhotic patients with wellmaintained liver function (Child-Pugh class A), the differences in the biochemical data between the patients with treatment requiring high-risk varices and those with a low risk of hemorrhage have not yet been clarified. Glycated proteins are known to reflect the plasma glucose level and glycated hemoglobin (HbA1c), is commonly used as an index of glycemic control in patients with diabetes mellitus ${ }^{(9,10)}$. Since the lifespan of erythrocytes is about 4 months, the HbA1c level is correlated with the level of glycemia for the past few months ${ }^{(11)}$. Another glycated protein, glycated albumin (GA), reflects the plasma glucose level during the past few weeks, because the turnover of albumin is about 3 weeks ${ }^{(12,13)}$. Although the ratio of $\mathrm{GA} / \mathrm{HbA} 1 \mathrm{c}$ is usually close to 3 , patients with chronic liver disease (CLD) have a shortened lifespan of erythrocytes due to the hypersplenism, thus resulting in lower $\mathrm{HbAlc}$ levels relative to the plasma glucose level. Conversely, the turn-over period of serum albumin in CLD patients is increased to compensate for the reduced albumin production. Therefore, the GA levels in CLD 
patients are higher relative to the degree of glycemia ${ }^{(14)}$. Since the HbA1c level is lower and the GA shows higher values, the $\mathrm{GA} / \mathrm{HbA} 1 \mathrm{c}$ ratio is assumed to be increased in CLD patients, especially in cirrhotic patients. In fact, the $\mathrm{GA} / \mathrm{HbA} 1 \mathrm{c}$ ratio in patients with CLD has been reported to show a reciprocal correlation with some indicators of hepatic function, irrespective of the mean plasma glucose levels ${ }^{(15)}$. It was previously examined the relationship between the histological grading of liver fibrosis and the GA/HbA1c ratio in patients with HCV-related CLD, and showed that the $\mathrm{GA} / \mathrm{HbA} 1 \mathrm{c}$ ratio was correlated with the progression of liver fibrosis ${ }^{(16)}$.

\section{AIM OF THE WORK:}

The aim of the study is to assess the value of glycated albumin to glycated hemoglobin ratio in the prediction of esophageal varices and assessing its risk of bleeding.

\section{Patients and Methods:}

This study was performed in Gastroenterology and Hepatology department AL-GLAA Military hospital during the period from September 2016 to August 2018 in order to evaluate glycated albumin to glycated hemoglobin ratio as a predictor for esophageal varices and its risk of bleeding.

The patients were divided according to presence of esophageal varices into five groups:

Group I: included 50 healthy controls not known to have chronic liver disease (C.L.D) referred to endoscopy unit for other complain e.g. GERD, dyspepsia, epigastric pain etc.

Group II: included 50 patients H.C.V. related chronic liver disease without O.V.

Group III: included 50 patients H.C.V. related chronic liver disease with O.V. grade I-II with no risky signs.

Group IV: included 50 patients H.C.V. related chronic liver disease with O.V. grade I-II with risky signs or grade III-IV.

Group V: included 50 patients H.C.V. related chronic liver disease with acute variceal bleeding.

After studying the results, we found that in order to produce a good value from this study, the groups of patients were re-divided into two types of division:

I- The patients were divided according to presence of risky esophageal varices or not into three groups:

Group A (control G I): included 50 healthy controls not known to have C.L.D referred to endoscopy unit for other complain e.g. GERD, dyspepsia, epigastric pain etc.

Group B Low risky OV (G II\&OV G III): included 50 patients H.C.V. related chronic liver disease without $\mathrm{O} . \mathrm{V}$ and 50 patients H.C.V. related chronic liver disease with O.V. grade I-II with no risky signs.

Group C High risky OV (G IV and $\boldsymbol{G} V$ ): included 50 patients H.C.V. related chronic liver disease with O.V. grade I-II with risky signs or grade III-IV and 50 patients H.C.V. related chronic liver disease with acute variceal bleeding.

II- The patients were divided according to presence of esophageal varices or not into three groups:

Group 1 (control group G I): included 50 healthy controls not known to have C.L.D referred to endoscopy unit for other complain e.g. GERD, dyspepsia, epigastric pain etc.

Group 2 no $O V(G$ II): included 50 patients H.C.V. related chronic liver disease without O.V.

Group 3 OV (G III, G IV and $G$ $V)$ : included 50 patients H.C.V. related chronic liver disease with O.V. grade I-II with no risky signs and 50 patients H.C.V. related chronic liver disease with O.V. grade I-II with risky signs or grade III-IV and 50 patients H.C.V. related chronic liver disease with acute variceal bleeding.

Application of inclusion and exclusion criteria was taking in consideration the Egyptian National HCV Control Program guide lines ${ }^{(8)}$. 
Inclusion criteria included the following: Patients with H.C.V. related chronic liver disease with different grades of varices according to each group in addition to control group.

Exclusion criteria included the following: Patients with medical history of diabetes mellitus, patients with C.L.D. due to other cause than H.C.V. e.g. H.B.V., bilharisiasis etc., patients known to be having diseases affecting serum albumin level as: C.L.D other than post hepatitis H.C.V., heart failure, lymphangiectasia and lymphedema, protein loosing enteropathy, renal amyloidosis, renal failure, ulcerative colitis and patients who refused to participate in the current study.

All patients were subjected to detailed history taking including age, sex, history of other comorbid conditions such as diabetes, hypertension, cardiac disease and renal failure. Clinical examination with special stress on: Liver and splenic size, ascites and signs of liver cell failure as jaundice, palmer erythema, lower limb edema or encephalopathy...etc. Laboratory investigations including: Complete blood count, serum total and direct bilirubin, AST, ALT, ALP and serum albumin PT, INR, serum creatinine and blood urea. Abdominal ultrasound commenting on liver size and echogenicity, splenic size, portal vein diameter and the status of ascites. Child and MELD score calculation. GA/HbA1c ratio calculation. Upper gastrointestinal endoscopy to evaluate the presence and degree of OV and portal gastropathy.

The study was done according to the ethical board of Al-Azhar University.

Statistical analysis:

Data were analyzed using Statistical Program

for Social Science (SPSS) version 15.0.

Quantitative data were expressed as mean \pm

standard deviation (SD). Qualitative data were expressed as frequency and percentage.
The following tests were done:

Chi-square test was used in the comparison between two groups with qualitative data.

Fisher exact test was used instead of the Chisquare test when the expected count in any cell found less than 5 .

A one-way analysis of variance (ANOVA): when comparing between more than two means.

Post Hoc test: was used for multiple comparisons between different variables.

Kruskall-Wallis test was used in the comparison between more than two groups with quantitative data and non-parametric distribution.

\section{Probability (P-value)}

- P-value $<0.05$ was considered significant.

- P-value $<0.001$ was considered as highly

significant.

- P-value >0.05 was considered insignificant.

\section{Results:}

Table (1) shows the UGE finding of the studied groups: group A (control G I): 15 patients $(30 \%)$ were free, 16 patients $(32 \%)$ were antral gastritis, 5 patients $(10 \%)$ were GERD G A, 5 patients (10\%) were GERD G B, 3 patients $(6 \%)$ were healed gastric ulcer, 6 patients (12\%) were pan gastritis. group B Low risky $O V(\boldsymbol{G} I I \& O V G \boldsymbol{I I I}): 50$ patients (50\%) were no OV, 22patients (22\%) were OV G I-II not risky, 28patients (28\%) were OV G II not risky. group C High risky $O V(G I V$ and $G V)$ : 11 patients (11\%) were OV G II risky banded, 34 patients (34\%) were OV G III risky banded, 20 patients $(20 \%)$ were OV G III-IV risky banded, 35 patients (35\%) were OV G IV risky banded. 
Tables (1):Upper GIT finding of the studied 250 patients according to risky esophageal varices or not

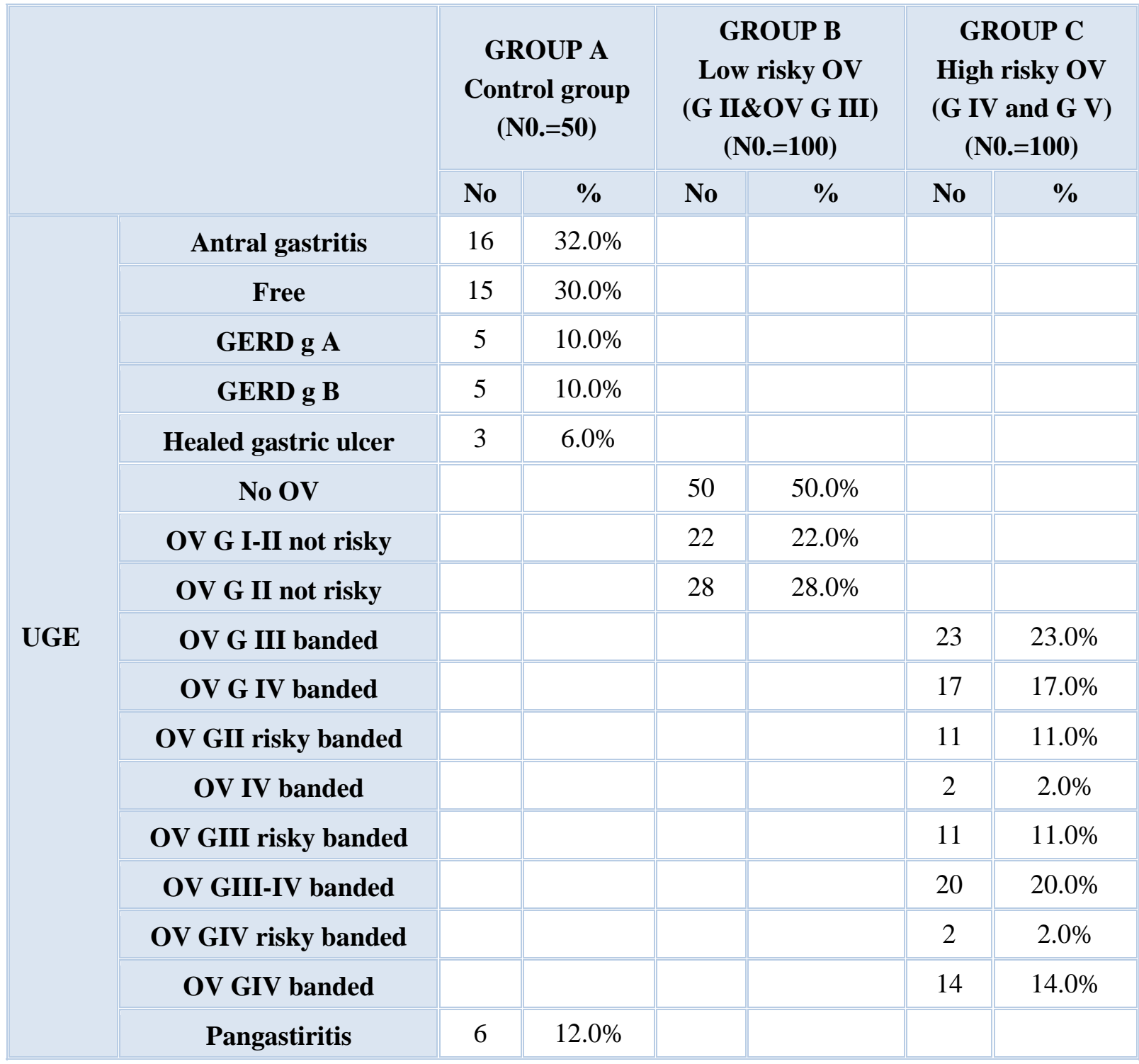

- Table (2): GA/HbA1C ratio of the studied 250 patients according to risky esophageal varices or not

\begin{tabular}{|c|c|c|c|c|c|}
\hline & $\begin{array}{c}\text { GROUP A } \\
\text { Control group } \\
(\mathbf{N 0 . = 5 0})\end{array}$ & $\begin{array}{c}\text { GROUP B } \\
\text { Low risky OV } \\
(\mathbf{G ~ I I \& O V ~ G ~ I I I )} \\
(\mathbf{N 0 . = 1 0 0})\end{array}$ & $\begin{array}{c}\text { GROUP C } \\
\text { High risky OV } \\
(\mathbf{G} \text { IV and G V) } \\
(\mathbf{N 0 . = 1 0 0})\end{array}$ & One way ANOVA \\
\hline & Mean \pm SD & Mean \pm SD & Mean \pm SD & F & p value \\
\hline GA/HbA1C ratio & $2.86 \pm 0.13$ & $3.49 \pm 0.26$ & $3.87 \pm 0.17$ & 402.13 & $<0.001$ \\
\hline
\end{tabular}

Table (2) shows the GA/HbAIC ratio of the studied groups: group A (control G I): GA/HbA1C ratio about $2.86 \pm 0.13$ group B Low risky $\boldsymbol{O V}(\boldsymbol{G}$ II\&OV $\boldsymbol{G}$ III): $\mathrm{GA} / \mathrm{HbA} 1 \mathrm{C}$ ratio about $3.49 \pm$ 0.26. group $\boldsymbol{C}$ High risky $\boldsymbol{O V}(\boldsymbol{G} \boldsymbol{I V}$ and $\boldsymbol{G} \boldsymbol{V})$ : $\mathrm{GA} / \mathrm{HbA} 1 \mathrm{C}$ ratio about $3.87 \pm 0.17$. There was statistically significant increase as regard $\mathrm{GA} / \mathrm{HbA} 1 \mathrm{C}$ ratio in group $\mathrm{C}$ in comparison to group $\mathrm{A}$ and B. P Value $(<0.001)$. 
Table (3): Child and MELD score of the studied 250 patients according to risky esophageal varices or not

\begin{tabular}{|c|c|c|c|c|c|c|}
\hline & & \multicolumn{2}{|c|}{$\begin{array}{c}\text { GROUP B } \\
\text { Low risky OV } \\
\text { (G II\&OV G III) } \\
(\text { N0.=100) }\end{array}$} & \multicolumn{2}{|c|}{$\begin{array}{c}\text { GROUP C } \\
\text { High risky OV } \\
(\text { G IV and G V) } \\
(\text { N0.=100) }\end{array}$} & \multirow{2}{*}{$\begin{array}{c}\text { Independent t test / } \\
\text { Chi square test } \\
\text { P value }\end{array}$} \\
\hline & & No & $\%$ & No & $\%$ & \\
\hline \multirow{3}{*}{ CHILD score } & (A) & 83 & $83.0 \%$ & 33 & $33.0 \%$ & \multirow{3}{*}{$<0.001$} \\
\hline & (B) & 17 & $17.0 \%$ & 63 & $63.0 \%$ & \\
\hline & (C) & 0 & $0.0 \%$ & 4 & $4.0 \%$ & \\
\hline MELD score & Mean \pm SD & \multicolumn{2}{|c|}{$15.78 \pm 2.87$} & \multicolumn{2}{|c|}{$17.92 \pm 3.90$} & $<0.001$ \\
\hline
\end{tabular}

Table (3) shows the child and MELD score of the studied groups:

Group B Low risky OV (G II\&OV G III): 83 patients (83\%) were child A, 17 patients (17\%) were child B with MELD score $15.78 \pm 2.78$. group $\boldsymbol{C}$ High risky $O V(G I V$ and $G \boldsymbol{V}): 33$ patients (33\%) were child A, 63 patients $(63 \%)$ were child B, 4 patients $(4 \%)$ were child C with MELD score $17.92 \pm 3.90$.

Table (4): Upper GIT finding of the studied 250 patients according to presence of esophageal varices or not.

\begin{tabular}{|c|c|c|c|c|c|c|c|}
\hline & & & $\begin{array}{l}\text { JP } 1 \\
\text { group } \\
\mathbf{5 0 )}\end{array}$ & & $\begin{array}{l}\text { OUP } 2 \\
\text { OV } \\
\text { II) } \\
=50)\end{array}$ & & $\begin{array}{l}\text { P 3 } \\
\text { oup } \\
\text { V,G V) } \\
\text { 50) }\end{array}$ \\
\hline & & No & $\%$ & No & $\%$ & No & $\%$ \\
\hline & Antral gastritis & 16 & $32.0 \%$ & & & & \\
\hline & Free & 15 & $30.0 \%$ & & & & \\
\hline & GERD g A & 5 & $10.0 \%$ & & & & \\
\hline & GERD g B & 5 & $10.0 \%$ & & & & \\
\hline & Healed gastric ulcer & 3 & $6.0 \%$ & & & & \\
\hline & No OV & & & 50 & $100.0 \%$ & & \\
\hline & OV G I-II not risky & & & & & 22 & $14.70 \%$ \\
\hline & OV G II not risky & & & & & 28 & $18.70 \%$ \\
\hline UGE & OV G III banded & & & & & 23 & $15.33 \%$ \\
\hline & OV G IV banded & & & & & 30 & $20.0 \%$ \\
\hline & OV GII risky banded & & & & & 11 & $7.30 \%$ \\
\hline & OV IV banded & & & & & 2 & $1.30 \%$ \\
\hline & OV GIII risky banded & & & & & 11 & $7.30 \%$ \\
\hline & OV GIII-IV banded & & & & & 20 & $13.30 \%$ \\
\hline & OV GIV risky banded & & & & & 2 & $1.30 \%$ \\
\hline & OV GIV banded & & & & & 1 & $7 \%$ \\
\hline & Pangastiritis & 6 & $12.0 \%$ & & & & \\
\hline
\end{tabular}

Table (6) shows the UGE finding of the studied groups: group 1 (control G I): 15 patients (30\%) were free, 16 patients (32\%) were antral gastritis, 5 patients (10\%) were GERD G A, 5 patients (10\%) were GERD G B, 3 patients (6\%) were healed gastric ulcer, 6 patients (12\%) were pan 
gastritis. Group 2 No $O V$ (G II): 50 patients (100\%) were no OV. Group 3 OV group (G III, G $I \boldsymbol{V}$, and $\boldsymbol{G} \boldsymbol{V}):$ 22patients (14.7\%) were OV G I-II not risky, 28 patients (18.7\%) were OV G II not risky, 11 patients $(7.3 \%)$ were OV G II risky banded, 34 patients (22.6\%) were OV G III risky banded, 20 patients (13.3\%) were OV G III-IV risky banded, 35 patients (23.3\%) were OV G IV risky banded.

Table (5): GA/HbA1C ratio of the studied 250 patients according to presence of esophageal varices or not.

\begin{tabular}{|c|c|c|c|c|c|}
\hline & $\begin{array}{c}\text { GROUP 1 } \\
\text { Control group } \\
(\mathbf{N 0 .}=\mathbf{5 0})\end{array}$ & $\begin{array}{c}\text { GROUP 2 } \\
\text { No OV } \\
(\mathbf{G} \text { II) } \\
(\mathbf{N 0 . = 5 0})\end{array}$ & $\begin{array}{c}\text { GROUP 3 } \\
\text { OV group } \\
(\mathbf{G ~ I I I , G ~ I V , G ~ V )} \\
\mathbf{( N 0 . = 1 5 0 )}\end{array}$ & One way ANOVA \\
\hline & Mean \pm SD & Mean \pm SD & Mean \pm SD & F & p value \\
\hline GA/HbA1C ratio & $2.86 \pm 0.13$ & $3.36 \pm 0.14$ & $3.79 \pm 0.24$ & 403.274 & $<0.001$ \\
\hline
\end{tabular}

- Table (7) shows GA/HbA1C ratio of the studied groups: group 1 (control G I): GA/HbA1C ratio about $2.86 \pm 0.13$.group 2 No $\mathrm{OV}(\boldsymbol{G}$ II): $\mathrm{GA} / \mathrm{HbA} 1 \mathrm{C}$ ratio about $3.36 \pm 0.14$ group 3 OV group $(\boldsymbol{G} I I I, G I V$, and $\boldsymbol{G} V$ ): $\mathrm{GA} / \mathrm{HbA} 1 \mathrm{C}$ ratio about $3.79 \pm 0.24$.There was statistically significant increase as regard $\mathrm{GA} / \mathrm{HbA} 1 \mathrm{C}$ ratio in group 3 in group 3 in comparison to group 1 and 2. P Value $(<0.001)$.

Table (6):Child and MELD score of the studied 250 patients according to presence of esophageal varices or not shown in

\begin{tabular}{|c|c|c|c|c|c|c|}
\hline & & \multicolumn{2}{|c|}{$\begin{array}{c}\text { GROUP } 2 \\
\text { No OV } \\
(\text { G II) } \\
\text { (N0.=50) }\end{array}$} & \multicolumn{2}{|c|}{$\begin{array}{c}\text { GROUP } 3 \\
\text { OV group } \\
\text { (G III,G IV,G V) } \\
\text { (N0.=150) }\end{array}$} & \multirow{2}{*}{$\begin{array}{c}\text { Independent t test / } \\
\text { Chi square test } \\
\text { P value }\end{array}$} \\
\hline & & No & $\%$ & No & $\%$ & \\
\hline \multirow{3}{*}{ CHILD score } & (A) & 50 & $100.0 \%$ & 66 & $44.0 \%$ & \multirow{3}{*}{$<0.001$} \\
\hline & (B) & 0 & $0.0 \%$ & 80 & $53.3 \%$ & \\
\hline & (C) & 0 & $0.0 \%$ & 4 & $2.7 \%$ & \\
\hline MELD score & Mean \pm SD & \multicolumn{2}{|c|}{$15.52 \pm 2.73$} & \multicolumn{2}{|c|}{$17.29 \pm 3.73$} & 0.002 \\
\hline
\end{tabular}

Table (6) shows the child and MELD score of the studied groups:

1. $\boldsymbol{G} 2$ No $\boldsymbol{O V}(\boldsymbol{G} \boldsymbol{I I}): 50$ patients $(100 \%)$ were child A with MELD score $15.78 \pm 2.78$. group 3 OV group ( $\boldsymbol{G} I I I, G I V$, and $\boldsymbol{G} V$ ): 66 patients $44 \%$ ) were child A, 80 patients $(53.3 \%)$ were child B, 4 patients $(2.7 \%)$ were child $C$ with MELD score $17.29 \pm 3.73$.

Table (7): Cut off point, sensitivity and specificity of GA/HbA1C ratio between $G 1$ (control group) and $\mathrm{G} 2$ (OV grade I)

\begin{tabular}{|c|c|c|c|c|c|}
\hline Cut off point & AUC & Sensitivity & Specificity & $+\mathbf{+ P V}$ & $\mathbf{- P V}$ \\
\hline$>3.08$ & 1.000 & 100.00 & 100.00 & 100.00 & 100.00 \\
\hline
\end{tabular}

This table shows that in $\mathrm{GA} / \mathrm{HbA1C}$ ratio:

- $\quad$ The cut of point of GA/HbA1C ratio $>3.08$

- Its sensitivity is $100 \%$ 
- Its specificity is $100 \%$

- The positive predictive value is $100 \%$

- The negative predictive value is $100 \%$

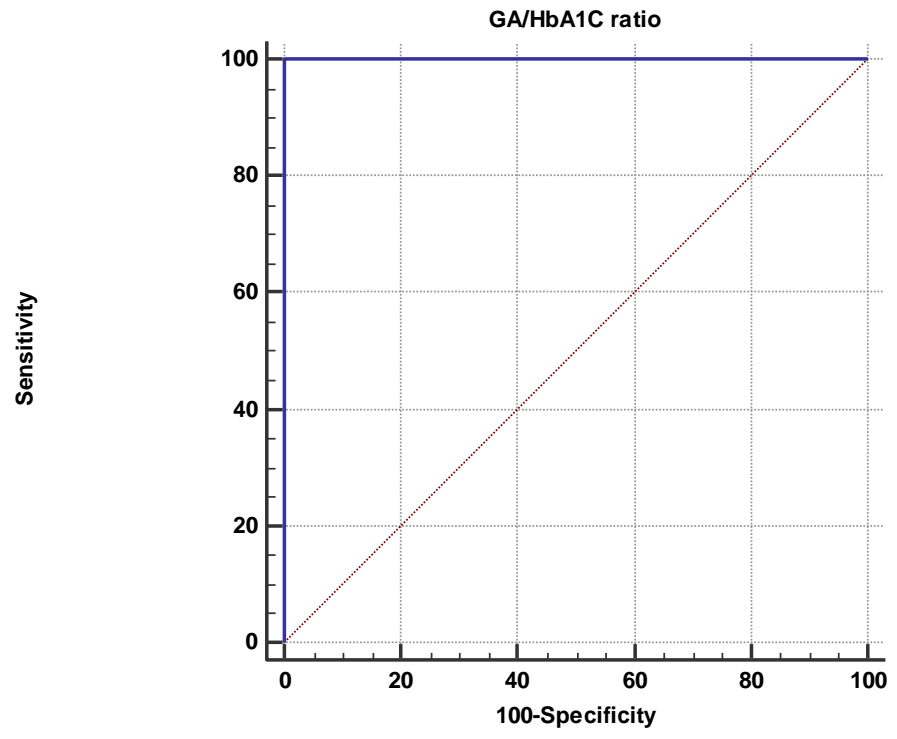

Figure (1): Roc curve of GA/HbA1C ratio in OV grade I

Table (8): Cut off point, sensitivity and specificity of GA/HbA1C ratio between $G B$ (not risky $O V)$ and $G C$ (risky $O V$ )

\begin{tabular}{|c|c|c|c|c|c|}
\hline Cut off point & AUC & Sensitivity & Specificity & +PV & -PV \\
\hline$>3.69$ & 0.796 & 97.00 & 60.00 & 82.9 & 90.9 \\
\hline
\end{tabular}

This table shows that in $\mathrm{GA} / \mathrm{HbAlC}$ ratio:

- $\quad$ The cut of point of GA/HbA1C ratio >3.69

- Its sensitivity is $97 \%$

- Its specificity is $60 \%$

- The positive predictive value is $82.9 \%$

- The negative predictive value is $90.9 \%$

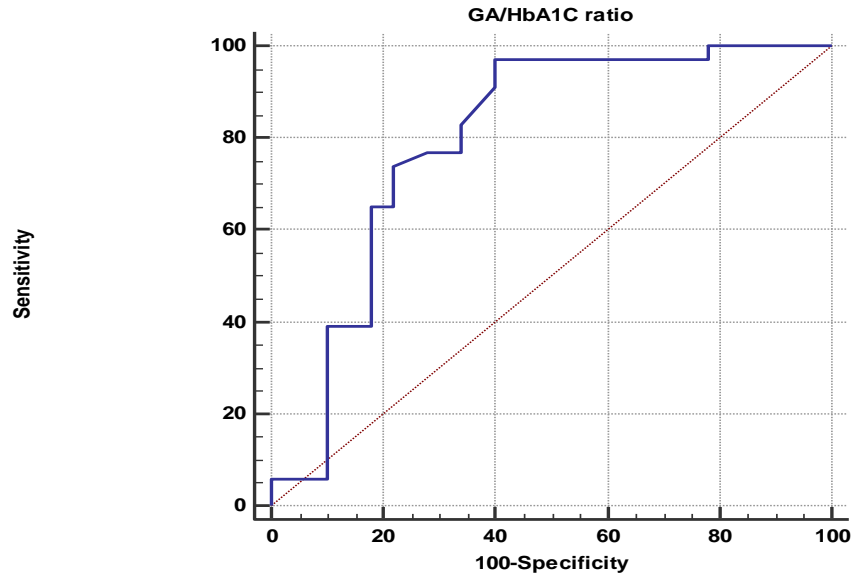

Figure (2): Roc curve of GA/HbA1C ratio in risky OV 


\section{Discussion:}

EGD is the gold standard method for evaluating varices to determine whether a patient should be treated to prevent a first variceal hemorrhage $(1,3,8)$. However, the need for repeating EGD is a burden for the patient with a high cost and a small, but significant, risk of complications. In addition, endoscopy has a relatively high interobserver variability for the diagnosis of small varices ${ }^{(2)}$. Therefore, many non-invasive or minimally invasive methods have been proposed to evaluate the presence/size of such varices. For example, a low platelet count has been consistently reported to be associated with the presence of varices or of large varices ${ }^{5,8,17}$, ${ }^{20)}$. In addition, many other tools, such as the Fibro-Test score ${ }^{(21,22)}$, transient elastography (FibroScan) ${ }^{(23,26)}$, multi-detector CT (MDCT) ${ }^{(27,30)}$ and capsule endoscopy ${ }^{(31,33)}$, have been proposed to predict the presence or size of the varices. However, none of the available methods completely meets the criteria of an ideal (accurate, simple, inexpensive and easily reproducible) method $\left(8,{ }^{29)}\right.$. Furthermore, previous reports regarding these noninvasive methods have not mentioned their predictive performance of the "red signs" on varices, although they are also important predictors of bleeding, as well as the size of the varices. Despite the fact that "small varices with severe red signs" have the same chance of bleeding as "large varices without red signs" (30), none of the non/minimally invasive methods, except capsule endoscopy, can evaluate patients for "red signs", thus indicating that they fail to detect small varices that are associated with a high risk of bleeding.

In the present study, we have shown that the $\mathrm{GA} / \mathrm{HbA} 1 \mathrm{c}$ ratio in $\mathrm{HCV}$-positive cirrhotic patients increases with the severity of the esophageal varices. The $\mathrm{GA} / \mathrm{HbA} 1 \mathrm{c}$ ratio is a simple and unique tool which is calculated based on the levels of the two glycated proteins and is associated with the endoscopic findings of esophageal varices. In particular, the $\mathrm{GA} / \mathrm{HbA} 1 \mathrm{c}$ ratio was found to be significantly increased in the patients with high-risk varices. Our findings should be of interest in that the ratio is elevated in the patients with a high risk of bleeding, including patients who have small varices with "red signs". Although the rate of change was relatively small, using the ratio may help predict the presence of any varices and discrimination of low-risk from high-risk of varices, because the $\mathrm{GA} / \mathrm{HbA} 1 \mathrm{c}$ ratio was the most significantly different among all of the parameters tested.

Bando et al. ${ }^{(15)}$ have previously reported that the GA/HbA1c ratio in patients with CLD has an inverse correlation with some indicators of hepatic function, regardless of the mean plasma glucose level, suggesting that the increase in the $\mathrm{GA} / \mathrm{HbA} 1 \mathrm{c}$ ratio reflects the reduction of liver function caused by the progression of liver cirrhosis. In addition, we found that the $\mathrm{GA} / \mathrm{HbA1c}$ ratio was elevated with the histological grade of liver fibrosis in patients with HCV-related CLD ${ }^{(16)}$.

In the present study, most patients were classified as cirrhotic patients with a wellmaintained liver function (Child-Pugh class A). Therefore, the elevation of the $\mathrm{GA} / \mathrm{HbA} 1 \mathrm{c}$ ratio may reflect the severity of the portal hypertension, rather than the progression of liver fibrosis. However, the degree of the portal hypertension does not always correlate with the size of varices and the risk of bleeding and future studies will be needed to clarify the reason for this discrepancy.

Sakai et al. (34) found that the $\mathrm{GA} / \mathrm{HbA}$ 1c ratio increases with the progression of the severity and bleeding risk of the varices.

EL-Hassafi et al ${ }^{(35)}$ concluded that $\mathrm{GA} / \mathrm{HbA} 1 \mathrm{c}$ ratio is a new promising marker for prediction esophageal varices in cirrhotic patients. Also it correlates well with the severity of liver cirrhosis.

In summary, we have shown that the $\mathrm{GA} / \mathrm{HbA} 1 \mathrm{c}$ ratio increases with the progression of the severity and bleeding risk of the varices. Since only a small number of patients were enrolled in the present study, it will be necessary to investigate the $\mathrm{GA} / \mathrm{HbA} 1 \mathrm{c}$ ratio in both larger and different populations.

\section{Conclusion:}

This study concluded that there is significant increase in $\mathrm{GA} / \mathrm{HbA} 1 \mathrm{c}$ ratio in high risky esophageal varices rather than low risky esophageal varices and in OV group rather than non-OV group. 


\section{References:}

1- De Franchis $R$ (2005): Evolving consensus in portal hypertension report of the Baveno IV consensus workshop on methodology of diagnosis and therapy in portal hypertension. J Hepatol., 43:167-176.

2- Garcia-Tsao G, Sanyal AJ, Grace ND, Carey W (2007): Prevention and management of gastroesophageal varices and variceal hemorrhage in cirrhosis. Hepatology , 46:922-938.

3- Garcia-Tsao G, Joseph L (2009): Management and treatment of patients with cirrhosis and portal hypertension: Recommendations from the department of veterans affairs hepatitis $\mathrm{C}$ resource center program and the national hepatitis $\mathrm{C}$ program. Am J Gastroenterol ., 104:1802-1829.

4- Orth-Italian Endoscopic Club for the study and treatment of esophageal varices(1988) : Prediction of the first variceal hemorrhage in patients with cirrhosis of the liver and esophageal varices.N Engl J Med.,319:983-989.

5- Pilette C, Oberti F, Aubé C et al. (1999): Non-invasive diagnosis of esophageal varices in chronic liver diseases. J Hepatol., 31:867-873.

6- Schepis $F$, Cammà $C$, Niceforo $D$ et al. (2001): Which patients should undergo endoscopic screening for oesophageal varices detection?Hepatology, 33:333-338.

7- Burton JR, Liangpunsakul S, Lapidus J, Giannini E, Chalasani N, Zaman A (2007): Validation of a multivariate model predicting presence and size of varices. J Clin Gastreoenterol., 41:609-615.

8- de Franchis R(2008): Non-invasive (and minimally invasive. Diagnosis of esophageal varices. J Hepatol., 49:520-527.

9- Koenig RJ, Peterson CM, Jones RL et al.(1976): Correlation of glucose regulation and hemoglobin AIc in diabetes mellitus. N Engl J Med., 295:417-420.

10- Bunn HF, Gabbay KH, Gallop PM (1978): The glycosylation of hemoglobin: relevance to diabetes mellitus, 20:21-27.

11- Tahara Y, Shima K (1995): Kinetics of HbA1c, glycated albumin, and fructosamine and analysis of their weight functions against preceding plasma glucose level. Diabetes Care, 18:440-447.

12- Dolhofer R, Wieland OH (1979): Glycosylation of serum albumin: Elevated glycosyl-albumin in diabetic patients. FEBS Lett .,103:282-286.

13- Guthrow CE, Morris MA, Day JF, Thorpe SR, Baynes JW (1979): Enhanced nonenzymatic glucosylation of human serum albumin in diabetes mellitus. Proc Natl Acad Sci USA., 76:4258-4261.

14- Koga M, Kasayama S (2010): Clinical impact of glycated albumin as another glycemic control marker. Endocrine J., 57:751-762.

15- Bando Y, Kanehara H, Toya D, Tanaka N, Kasayama S, Koga M(2009): Association of serum glycated albumin to glycated hemoglobin A1c ratio with hepatic function tests in patients with chronic liver disease. Ann Clin Biochem .,46:368-372.

16- Aizawa N, Enomoto H, Imanishi $H$ et al.(2012): Elevation of the glycated albumin to glycated hemoglobin ratio during the progression of $\mathrm{HCV}$ related liver fibrosis. World J Hepatol .,4(1):11-17.

17- Madhotra R, Mulcahy HE, Willner I, Reuben A (2002): Prediction of esophageal varices in patients with cirrhosis. J Clin Gastroenterol ., 34:81-85.

18- Zein CO, Lindor KD, Angulo $P$ (2004): Prevalence and predictors of esophageal varices in patients with primary sclerosing cholangitis. Hepatology , 39:204-210.

19- Giannini E, Botta $F$, Borro $P$ et al. (2003): Platelet count/spleen diameter ratio: proposal and validation of a non-invasive parameter to predict the presence of ooesophagealvarices in patients with liver cirrhosis. Gut , 52:1200-1205.

20- Giannini EG, Zaman A, Kreil A et al. (2006): Platelet count/spleen 
diameter ratio for the non invasive diagnosis of oesophageal varices. Results of a multicenter, prospective, validation study. Am J Gastroenterol ., 101:2511-2519.

21- Imbert-Bismut F, Ratziu V, Pieroni L, Charlotte F, Benhamou Y, Poynard T(2001): Biochemical markers of liver fibrosis in patients with hepatitis $\mathrm{C}$ virus infection: a prospective study. Lancet, 357:10691075.

22- Thabut $\mathrm{D}$, Trabut JB, Massard $\mathrm{J}$ et al. (2006): Non-invasive diagnosis of large esophageal varices by fibro-test in patients with cirrhosis: a preliminary retrospective study. Liver Int., 26:271- 278.

23- Sandrin L, Fourquet B, Hasquenoph JM et al. (2003): Transient elastography: a new noninvasive method for assessment of hepatic fibrosis. Ultrasound Med Biol ., 29:1705-1713.

24- Bureau C, Metivier S, Peron JM et al. (2008): Transient elastography accurately predicts presence of clinically significant portal hypertension in patient with chronic liver disease. Aliment Pharmacol Ther., 27:1261-1268.

25- Vizzutti F, Arena U, Romanelli RG et al. (2007): Liver stiffness measurement predicts severe portal hypertension in patients with HCVrelated cirrhosis. Hepatology , 45:1290-1297.

26- Kazemi F, Kettaneh A, N'kontchou G et al. (2006): Liver stiffness measurement selects patients with cirrhosis at risk of bearing large esophageal varices. J Hepatol ., 45:230-235.

27- Kang HK, Jeong YY, Choi JH et al. (2002): Three-dimensional multidetector row CT portal venography in the evaluation of portosystemic collateral vessels in liver cirrhosis. Radiographics, 22:1053-1061.

28- Kim YJ, Raman SS, Yu NC, To'o KJ, Jutabha R, Lu DS (2007): Esophageal varices in cirrhotic patients: evaluation with liver CT. Am J Roentgenol ., 188:139-144.
29- Kim SH, Kim YJ, Lee JM et al. (2007): Esophageal varices in patients with cirrhosis: multi-detector CT esophagography - comparison with endoscopy. Radiology, 242:759-768.

30- Perri RE, Chiorean MV, Fidler JL et al. (2008): A prospective evaluation of computerized tomographic (CT scanning as a screening modality for esophageal varices. Hepatology , 47:1587- 1594.

31- Eisen GM, Eliakim R, Zaman A et al.(2006): The accuracy of PillCam ESO capsule endoscopy versus conventional upper endoscopy for the diagnosis of esophageal varices: a prospective three center pilot study. Endoscopy, 38:31-35.

32- Lapalus MG, Dumortier J, Fumex F et al.(2006): Esophageal capsule endoscopy versus esophagogastroduodenoscopy for evaluating portal hypertension: a prospective comparative study of performance and tolerance. Endoscopy, 38:36-41.

33- Pena LR, Cox T, Koch AG, Bosch A (2008): Study comparing esophageal capsule endoscopy versus EGD in the detection of varices. Dig Liver Dis., 40:216-223.

34- Sakai Y, Enomoto H, Aizawa $\mathrm{N}$ et al. (2012): Relationship between Elevation of Glycated Albumin to Glycated Hemoglobin Ratio in Patients with a High Bleeding Risk of Esophageal Varices. HepatoGastroenterology, 59:2280-2284.

35- Mohammed Y, Gamal A, Moyassar A, Said A, Esraa W (2014) : glycated albumin to glycated haemoglobin ratio in patients with liver cirrhosis and its relation to severity of cirrhosis and risk of bleeding of esophageal varices, J. of the Egypt. SOC. Endocrine., Metab. \& Diab., 46(1):129-136. 